\title{
Novel Functional Role of Heat Shock Protein 90 in Mitochondrial Connexin 43-Mediated Hypoxic Postconditioning
}

\author{
Rong-Hui Tu ${ }^{a}$ Qing-Jie Lib ${ }^{b}$ Zheng Huang ${ }^{b} \quad Y^{2} \mathrm{He}^{\mathrm{a}} \quad$ Jian-Jun Meng ${ }^{\mathrm{c}}$ \\ Hui-Lei Zheng ${ }^{\mathrm{a}}$ Zhi-Yu Zenga,b Guo-Qiang Zhonga,b \\ ${ }^{a}$ Department of Geriatric Cardiology, ${ }^{b}$ Department of Cardiology, ${ }^{\mathrm{C}}$ Geriatric health care center, First \\ Affiliated Hospital, Guang Xi Medical University, Nanning, China
}

\section{Key Words}

Hsp90 • Hypoxic postconditioning $•$ Connexin $43 \cdot$ ROS signaling $•$ Apoptosis

\begin{abstract}
Background/Aims: Previous studies have shown that heat shock protein 90 (HSP90)-mediated mitochondrial import of connexin $43(\mathrm{C} \times 43)$ is critical in preconditioning cardioprotection. The present study was designed to test whether postconditioning has the same effect as preconditioning in promoting $\mathrm{C} \times 43$ translocation to mitochondria and whether mitochondrial HSP90 modulates this effect. Methods: Cellular models of hypoxic postconditioning (HPC) from rat heart-derived $\mathrm{H} 9 \mathrm{c} 2$ cells and neonatal rat cardiomyocytes were employed. The effects of HPC on cardiomyocytes apoptosis were examined by flow cytometry and Hoechst 33342 fluorescent staining. Reactive oxidative species (ROS) production was assessed with the peroxide-sensitive fluorescent probe $2^{\prime}, 7^{\prime}$-dichlorofluorescin in diacetate (DCFH-DA). The anti- and pro-apoptotic markers Bcl-2 and Bax, HSP90 and Cx43 protein levels were studied by Western blot analysis in total cell homogenate and sarcolemmal and mitochondrial fractions. The effects on HPC of the HSP90 inhibitor geldanamycin (GA), ROS scavengers superoxide dismutase (SOD) and catalase (CAT), and small interfering RNA (siRNA) targeting Cx43 and HSP90 were also investigated. Results: HPC significantly reduced hypoxia/reoxygenation $(\mathrm{H} / \mathrm{R})$-induced cardiomyocyte apoptosis. These beneficial effects were accompanied by an increase in Bcl-2 levels and a decrease in Bax levels in both sarcolemmal and mitochondrial fractions. HPC with siRNA targeting Cx43 or the ROS scavengers SOD plus CAT significantly prevented ROS generation and HPC cardioprotection, but HPC with either SOD or CAT did not. These data strongly supported the involvement of $\mathrm{Cx} 43$ in HPC cardioprotection, likely via modulation of the ROS balance which plays a central role in HPC protection. Furthermore, HPC increased total and mitochondrial levels of HSP90 and the mitochondria-to-sarcolemma ratio of Cx43; blocking the function of HSP90 with the HSP90 inhibitor geldanamycin (GA) or siRNA targeting HSP90 prevented the protection of HPC and the HPC-induced association of $\mathrm{Cx} 43$, indicating that mitochondrial HSP90 was important for mitochondrial translocation of $\mathrm{Cx} 43$ Q. Li contributed equally to this work.

\begin{tabular}{ll}
\hline Guo-Qiang Zhong & Department of Cardiology, First Afiliated Hospital, Guang Xi Medical University, \\
and Zhi-Yu Zeng & 22 Shuangyong Road, Nanning, Guangxi, (Republic of China) \\
& Tel. +86771-5356618, +86771-5356592, E-Mail guoq_zhong@163.com, zy126zeng@126.com
\end{tabular}
\end{abstract}


during HPC. Conclusion: Mitochondrial HSP90 played a central role in HPC cardioprotection, and its activity was linked to the mitochondrial targeting of $\mathrm{C} \times 43$, the activation of which triggered ROS signaling and the subsequent reduction of redox stress. Consequently, its target gene, $\mathrm{Bcl}-2$, was upregulated, and proapoptotic Bax was inhibited in the sarcolemma and mitochondria, ultimately attenuating $\mathrm{H} / \mathrm{R}$-induced cardiomyocyte apoptosis. These data reveal a novel mechanism of HPC protection

(C) 2017 The Author(s)

Published by S. Karger AG, Basel

\section{Introduction}

The reduction of ischemia-reperfusion (I/R) injury is a major challenge for acute myocardialinfarction. Arrhythmias, "myocardial stunning", as wellas cardiomyocyte apoptosis initiated during the crucial early moments of reperfusion are sometimes extremely severe or fatal and diminish the benefits of reperfusion. Within the last decade, many basic science and clinical studies have confirmed that ischemic postconditioning, whereby brief periods of ischemia were applied during the start of reperfusion, significantly reduced myocardial injury [1-4]. Postconditioning-related cardioprotective mechanisms are currently under investigation, and emerging data provide evidence that reactive oxidative species (ROS) signaling during early reperfusion is crucial for postconditioning-induced cardioprotection [5-8]. ROS are generated during the early phase of reflow and are considered a major cause of reperfusion injury $[9,10]$, although this conclusion is still debated. In fact, current literature describes both protective and deleterious effects of ROS. However, the precise mechanisms for the controversial roles of ROS in myocardial I/R injury and cardioprotection have not yet been fully elucidated.

Connexin 43 ( $\mathrm{Cx} 43)$ is the predominant protein forming gap junctions in ventricular myocardium and is essential for intercellular electrical conduction and cell survival in mammals [11]. Apart from its localization at the sarcolemma, Cx43 is also expressed in mitochondria in cardiomyocytes [12]. Previous studies have indicated that mitochondrial $\mathrm{Cx} 43$ plays an essential role in cardioprotection during preconditioning because it appears to be a prerequisite for mitochondrial generation of a specific ROS signal $[13,14]$. However, whether Cx43 is involved in postconditioning-induced cardioprotection and the corresponding details is unclear.

Heat shock protein 90 (HSP90), one of the most abundant and conserved molecular chaperones, is essential for the integrity and function of numerous signaling client proteins. HSP90 is activated by cellular stresses and can facilitate mitochondrial import of cytosolic proteins during ischemic preconditioning $[15,16]$. The action of HSP90 in mitochondrial targeting is a novel cellular function of this chaperone. Our laboratory recently demonstrated that HSP90 is critical for postconditioning-induced cardioprotection and that its activity may be linked to mitochondrial targeting of PKCepsilon [17]. It is well known that HSP90mediated mitochondrial import of $\mathrm{Cx} 43$ as well as ATP-sensitive $\mathrm{K}^{+}$channels are critical during the cardioprotection of preconditioning $[15,18]$. However, it is not clear whether HSP90-mediated mitochondrial import of Cx43 is responsible for the cardioprotection of postconditioning. Moreover, few investigations have been conducted to determine the role of mitochondrial HSP90 in postconditioning.

Therefore in the present study, we tested the hypothesis that hypoxia postconditioning (HPC) attenuated hypoxia/reoxygenation (H/R)-induced cardiomyocyte injury and apoptosis via mitochondrial HSP90, which was linked to mitochondrial targeting of $\mathrm{Cx} 43$, ultimately triggering small amounts of ROS signaling in mitochondria. Specifically, the effects of HPC on cardiomyocyte apoptosis were examined. Levels of anti- and pro-apoptosis markers, HSP90 as well as $\mathrm{Cx} 43$ proteins in total cellular and sarcolemmal and mitochondrial fractions were examined by Western blot analysis. The effects on HPC of the HSP90 inhibitor geldanamycin (GA), ROS scavengers superoxide dismutase (SOD) and catalase (CAT), and small interfering RNA (siRNA) targeting Cx43 and HSP90 were also investigated. 


\section{Cellular Physiology Cell Physiol Biochem 2017;44:982-997 \begin{tabular}{l|l} 
and Biochemistry & DOI: 10.1159/000485399 \\
Published online: November 27, 2017 & $\begin{array}{l}\text { (c) } 2017 \text { The Author(s). Published by S. Karger AG, Basel } \\
\text { www.karger.com/cpb }\end{array}$
\end{tabular}}

Tu et al.: Heat Shock Protein 90 in Hypoxic Postconditioning

\section{Materials and Methods}

The experimental animals were handled in compliance with the National Institutes of Health Guide for the Care and Use of Laboratory Animals. The experimental protocols were approved by the Guangxi Medical University Animal Care and Use Committee.

\section{Neonatal rat cardiomyocyte culture and hypoxia/reoxygenation}

One to three-day-old Sprague-Dawley rats were used for the primary cardiomyocyte cultures. The hearts were rapidly excised, minced, and dissociated with $0.125 \%$ trypsin (Sigma Chemical Company, St. Louis, MO, USA). Then, $1 \times 10^{6}$ neonatal cardiomyocytes were plated on $35 \mathrm{~mm}$ dishes containing DMEM (Gibco, Gaithersburg, USA) supplemented with $10 \%$ fetal bovine serum. After $24 \mathrm{~h}$ in a humidified incubator with $95 \%$ air and $5 \% \mathrm{CO}_{2}$ (normoxic situation) at $37^{\circ} \mathrm{C}$, the culture medium was replaced with DMEM supplemented with $10 \%$ FBS containing $10 \mu \mathrm{M}$ cytosine arabinoside to eliminate noncardiomyocytes. After culturing for 5-6 days in normoxic DMEM, the culture medium was replaced with fresh 1\% FBS-DMEM, and the cells were transferred to an airtight chamber containing $95 \% \mathrm{~N}_{2}$ and $5 \% \mathrm{CO}_{2}$ for $3 \mathrm{~h}$ of hypoxia. At the end of this period, the cells were rapidly transferred to a normoxic incubator for $6 \mathrm{~h}$ of reoxygenation [19].

\section{Small interfering RNAs}

The small interfering RNA (siRNA) oligonucleotides that specifically target rat Cx43 or HSP90 ( $\alpha$ and $\beta$ isoforms) were prepared and synthesized by Ambion Inc. (Austin, TX, USA). A negative control siRNA (scrambled) was included to monitor nonspecific effects.

\section{H9c2 cell culture and transfection}

Rat heart-derived H9c2 cells (ATCC, Manassas, VA, USA) were cultured in DMEM supplemented with $10 \%$ fetal bovine serum, $2 \mathrm{mM}$ glutamine, $100 \mathrm{U} / \mathrm{ml}$ penicillin and $100 \mathrm{mg} / \mathrm{mL}$ streptomycin. H9c2 cells were transfected with siRNA using X-Tremegene siRNA transfection reagent [15]. At 48 to $72 \mathrm{~h}$ after transfection, Western blotting was performed to examine the knockdown of Cx43 and HSP90.

\section{Hypoxic postconditioning and experimental protocols}

The general experimental protocols employed are described as follows: 1) control group: neonatal rat cardiomyocytes maintained in normoxic culture with 1\% FBS-DMEM for $9 \mathrm{~h}$; 2) H/R group: cardiomyocytes and H9c2 cells subjected to $3 \mathrm{~h}$ hypoxia followed by $6 \mathrm{~h}$ reoxygenation; 3) HPC group: cardiomyocytes and $\mathrm{H} 9 \mathrm{c} 2$ cells subjected to hypoxia for $3 \mathrm{~h}$, followed by three cycles of $5 \mathrm{~min}$ reoxygenation and $5 \mathrm{~min}$ hypoxia and then reoxygenation for $6 \mathrm{~h}$; 4) HPC + GA group: addition of HSP90 inhibitor GA (Sigma-Aldrich, St. Louis, MO, dissolved in 0.1\% DMSO solution, $1 \mu \mathrm{M}) 5 \mathrm{~min}$ before HPC; 5) HPC + HSP90-siRNA group: HPC treatment of H9c2 cells at 48-72 h after being transfection with HSP90 siRNA; 6) HPC + SOD group: addition of SOD (Sigma-Aldrich, St. Louis, MO, $100 \mathrm{U} / \mathrm{mL}) 5 \mathrm{~min}$ before HPC; 7) HPC+ CAT group: addition of CAT (Sigma-Aldrich, St. Louis, MO, $120 \mathrm{U} / \mathrm{mL}$ ) $5 \mathrm{~min}$ before HPC; 8) HPC + SC group: addition of SOD and CAT 5 min before HPC; 9) HPC + Cx43-siRNA group: HPC treatment of H9c2 cells at 48-72 h after being transfection with Cx43 siRNA; and 10) HPC + C-siRNA group: HPC treatment of H9c2 cells at 48-72 h after being transfection with negative control siRNA. At the end of each experiment, the cells were processed for analyses of apoptosis and mitochondrial ROS production. Anti- and pro-apoptosis markers Bcl-2 and Bax, HSP90 and Cx43 protein levels were also assessed in total cellular and sarcolemmal and mitochondrial fractions by Western blot analysis.

\section{Identification of cell apoptosis by flow cytometry}

Cell apoptosis was assessed by flow cytometry using the Annexin V-FITC Apoptosis Detection Kit with propidium iodide (PI). The cells were stained with Annexin V-FITC (Roche Diagnostics GmbH, Mannheim, Germany) and PI (BD Pharmingen) in accordance with the manufacturer's instructions. Briefly, cardiomyocytes and H9c2 cells were detached from each well by incubation with trypsin $(0.25 \mathrm{mg} / \mathrm{mL})$, washed with cold PBS, resuspended in binding buffer containing $20 \mu \mathrm{L}$ Annexin V-FITC and $1 \mu \mathrm{g} / \mathrm{mL}$ PI, and incubated for $15 \mathrm{~min}$ at room temperature in the dark. The samples were analyzed using a fluorescenceactivated cell sorting flow cytometer (Becton Dickinson; San Jose, CA) set to collect a total of 10, 000 counts. Cells stained with Annexin V-FITC alone were considered apoptotic, whereas cells that double stained with 


\section{Cellular Physiology Cell Physiol Biochem 2017;44:982-997

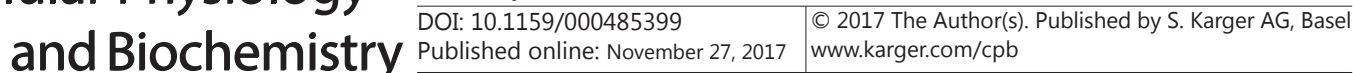 \\ Tu et al.: Heat Shock Protein 90 in Hypoxic Postconditioning}

Annexin V-FITC and PI were considered late apoptotic or necrotic. Data analysis was performed using the Cell Quest Software Program.

\section{Detection of apoptosis by fluorescence microscopy}

To assess nuclear morphology changes associated with apoptosis, Hoechst 33342 fluorescent dye (Thermo Fisher Scientific Inc. Rockford, IL, USA, $1 \mu \mathrm{g} / \mathrm{mL}$ ) was used. Briefly, the cells were grown on glass slides and fixed in $3.7 \%$ buffered formaldehyde for $10 \mathrm{~min}$ at room temperature. They were then stained with Hoechst 33342 for 15 min after washing with deionized water. Apoptotic cells displayed an abnormal nuclear morphology, including nuclear condensation, cell shrinkage, nuclear fragmentation, and chromosomal DNA fragmentation. The cells were analyzed using an Axiostar Plus fluorescence microscope (Karl Zeiss Microscopy GmbH, Jena, Germany).

\section{Preparation of mitochondria}

Mitochondria were prepared from neonatal rat cardiomyocytes and H9c2 cells by differential centrifugation using a modification of a published procedure [20]. At the end of reoxygenation, the cells were scraped, washed, suspended in an ice-cold buffer containing $250 \mathrm{mM}$ sucrose, $5 \mathrm{mM}$ EDTA, $5 \mathrm{mM}$ HEPES, and protease inhibitor cocktail, and then homogenized $30 \mathrm{~s}$ on ice using an ice-cold Potter. The homogenate was centrifuged twice at $1000 \mathrm{~g}$ for $10 \mathrm{~min}$ at $4^{\circ} \mathrm{C}$ to remove nuclei and debris. The supernatants were centrifuged for $30 \mathrm{~min}$ at $12,000 \mathrm{~g}$ at $4^{\circ} \mathrm{C}$. The mitochondrial pellet was suspended in homogenizing buffer and further purified by 2 additional centrifugation cycles $\left(8,500 \mathrm{~g}, 10\right.$ minutes, $\left.4^{\circ} \mathrm{C}\right)$, and the final pellet was resuspended in solution buffer (in mM: $150 \mathrm{KCl}, 5 \mathrm{~K}$-HEPES, $1 \mathrm{CaCl}_{2}, \mathrm{pH}$ 7.2). The protein level was determined using Bradford's method [21].

\section{Preparation of sarcolemmal protein}

Sarcolemmal protein from neonatal rat cardiomyocytes and H9c2 cells was obtained by differential centrifugation using the membrane Protein Extraction Kit (Biovison and Abcam) according to the manufacturer's instructions. Briefly, at the end of reoxygenation, the cells were washed, scraped, suspended in a membrane protein extraction buffer (250 mM sucrose, $10 \mathrm{mM}$ HEPES-KOH, $1 \mathrm{mM}$ EGTA, $1 \mu \mathrm{l}$ protease inhibitors, and $1 \mu \mathrm{l}$ DTT), homogenized, and spun (14000 g, 10 minutes, $\left.4^{\circ} \mathrm{C}\right)$. The supernatant containing the sarcolemmal membrane was placed in a water bath $\left(10\right.$ minutes, $\left.37^{\circ} \mathrm{C}\right)$ and then pelleted $(13000 \mathrm{~g}, 5$ minutes, $4^{\circ} \mathrm{C}$ ). The sarcolemmal pellet was suspended in sterile water and further purified by 2 additional centrifugation $\left(14000 \mathrm{~g}, 10\right.$ minutes, $\left.4^{\circ} \mathrm{C}\right)$ and water bath $\left(10\right.$ minutes, $\left.37^{\circ} \mathrm{C}\right)$ cycles. The final pellet was resuspended in anhydrous acetone solution, and the protein level was determined by Bradford's method.

\section{Determination of mitochondrial ROS production}

Mitochondrial ROS production was assessed with the peroxide-sensitive fluorescent probe $2^{\prime}, 7^{\prime}$-dichlorofluorescin in diacetate (DCFH-DA) (GENMED, GMS10016.2) as described previously [22, 23]. DCFH-DA is converted by intracellular esterases to DCFH, which is oxidized into the highly fluorescent dichlorofluorescin (DCF) in the presence of a proper oxidant and can then be assessed using a fluorescence microplate reader (Tecan Infinite M200, Tecan, Austria). In brief, the freshly prepared mitochondria were incubated with DCFH-DA $(10 \mu \mathrm{mol} / \mathrm{L})$ in serum-free DMEM for $20 \mathrm{~min}$ at $37^{\circ} \mathrm{C}$ in the dark. The fluorescence in the supernatant was measured using a microplate reader at specific excitation/emission wavelengths of $488 / 525 \mathrm{~nm}$. The results are expressed as the fluorescence of DCF per milligram of protein.

\section{Western blotting}

Immunoblot analysis was performed using total protein, sarcolemmal and mitochondrial fractions. To confirm the purity of the sarcolemmal or mitochondrial fractions, antibodies against the sarcolemmal marker ( $\mathrm{Na}^{+}-\mathrm{K}^{+}$-ATPase) and the mitochondrial marker cytochrome c oxidase IV (COXIV) were used. In brief, the purified sarcolemmal and mitochondrial fractions were denatured in sample buffer, and then equal amounts of proteins were separated by SDS-polyacrylamide on 8\% (for HSP90) or 12\% (for GAPDH, Bcl-2, $\mathrm{Bax}, \mathrm{Cx} 43, \mathrm{Na}^{+}-\mathrm{K}^{+}$-ATPase and COXIV) gels and transferred to nitrocellulose membranes. The membranes were blocked with 5\% nonfat milk in Tris-buffered saline-Tween 20 (TBST, $150 \mathrm{mM} \mathrm{NaCl}, 20 \mathrm{mM}$ Tris$\mathrm{HCl}, 0.1 \%$ Tween 20, $\mathrm{pH}$ 7.4), washed twice in TBS-T and incubated with primary antibodies for $2 \mathrm{~h}$ at room temperature or overnight at $4^{\circ} \mathrm{C}$. The following primary antibodies were used: anti-HSP90, anti-Cx43, 
anti-phospho-(Ser-262)-Cx43, anti-COXIV, anti-GAPDH, anti-Na+- ${ }^{+}$-ATPase, anti-Bcl-2, and anti-Bax (BD Biosciences, Milano, Italy; Santa Cruz, CA, USA; and Sigma-Aldrich, MO, USA). After washing, the membranes were incubated with peroxidase-conjugated secondary antibodies for $1 \mathrm{~h}$ at room temperature, visualized using the ECL detection system and quantified using ImageJ (NIH).

\section{Statistical analysis}

Data were analyzed using SPSS 13.0 (SPSS Inc., Chicago, IL, USA) and are presented as the mean \pm SD of at least four independent experiments. The unpaired t-test was used to compare groups. Multiple group means were compared by one-way analysis of variance followed by the LSD post-hoc test. A p-value $<0.05$ was considered significant.

\section{Results}

\section{Role of HSP90 in cell apoptosis during hypoxic postconditioning}

To determine whether HSP90 is involved in postconditioning, we first examined the levels of HSP90 in the total cellular fraction of postconditioned cardiomyocytes. As shown in Fig. 1A, HPC significantly increased the levels of HSP90 protein compared with the H/R group $(101.2 \pm 1.2 \%$ vs. $62.7 \pm 1.3 \%$; $\mathrm{P}<0.05)$. As mitochondria play pivotal roles in the cascade of events associated with postconditioning, we further examined HSP90 expression in the mitochondrial fraction and observed a significant increase in mitochondrial HSP90 in the HPC but not in the H/R group ( $\mathrm{P}<0.05$; Fig. 1B). Concomitantly, the number of apoptotic cardiomyocytes identified by Annexin V-FITC and Hoechst 33342 staining was significantly lower in the HPC group compared with the H/R group $(21.1 \pm 1.4 \%$ vs. $48.2 \pm 1.3 \%$ and $21.6 \pm 1.1 \%$ vs. $42 \pm 1.1 \%$, respectively; $\mathrm{P}<0.05$; Fig. $2 \mathrm{~A} \& \mathrm{C}$ ). These observations suggested that HPC inhibited cardiomyocytes apoptosis by increasing HSP90 expression.

Fig. 1. Expression of HSP90 in cardiomyocytes with hypoxic postconditioning (HPC). (A), (B) Representative Western blots showing the expression of HSP90 in the total cell homogenate and mitochondrial fraction in cardiomyocytes with or without the treatment with HPC and HPC plus geldanamycin (GA, 1 $\mu \mathrm{M}) ; \mathrm{GAPDH}$ and COXIV were used to demonstrate equal protein loading, respectively. (C) Graphic representation of HSP90 expression; values in the graphs represent the mean \pm standard deviation; ${ }^{*} \mathrm{P}<0.05$ versus control group, ${ }^{\circledR} \mathrm{P}<0.05$ versus $\mathrm{H} / \mathrm{R}$ group, ${ }^{\mathrm{P}}<0.05$ versus HPC group; $\mathrm{n}=4$ for each group.

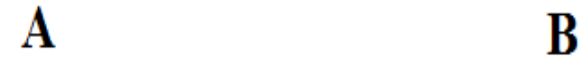

Total cell homogenate

C $\quad \mathrm{H} / \mathrm{R} \quad \mathrm{HPC} \quad \mathrm{HPC}+\mathrm{GA}$
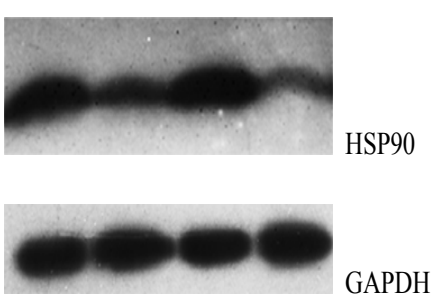

C

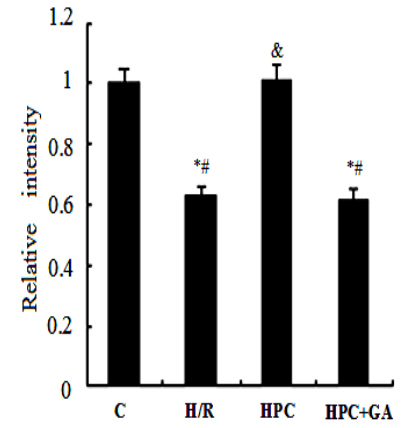

B

Fig. 2. Effects of hypoxic postconditioning (HPC) with or without treatment with the HSP90 inhibitor geldanamycin (GA, $1 \mu \mathrm{M})$ or ROS scavengers [superoxide dismutase (SOD, 100 $\mathrm{U} / \mathrm{mL}$ ), catalase (CAT, $120 \mathrm{U} / \mathrm{mL}$ ), SOD plus CAT] or siRNA targeting HSP90 and Cx43 (H SP 90 - siRNA, Cx43-siRNA) on apoptosis after subjecting cardiomyocytes and H9c2 cells to hypoxia/reoxygenation (H/R). (A) Flow cytometry analysis of neonatal rat cardiomyocyte apoptosis with or without treatment with GA, SOD, CAT, or SOD plus CAT (the lower right quadrant denotes the apoptotic cells). (B) Flow cytometry analysis of H9c2 cells apoptosis with or without treatment with HSP90-siRNA or Cx43-siRnA. (C), (D) Assessment

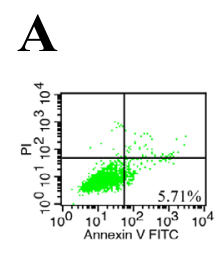

$\mathrm{C}$

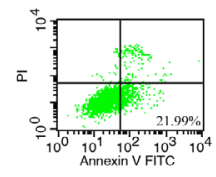

$\mathrm{HPC}+\mathrm{CAT}$

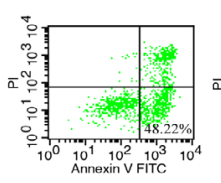

$\mathrm{H} / \mathrm{R}$

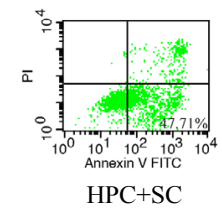

B

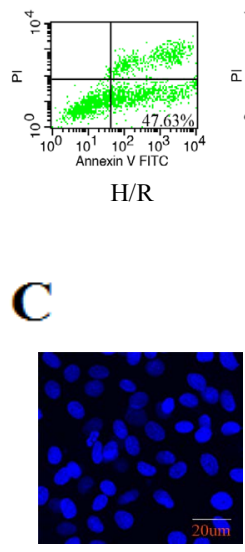

C

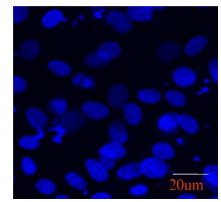

$\mathrm{HPC}+\mathrm{CAT}$

D

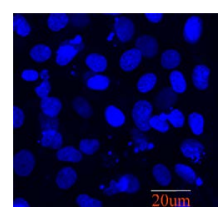

$\mathrm{H} / \mathrm{R}$

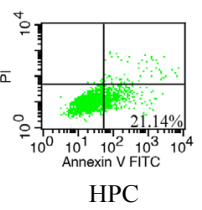

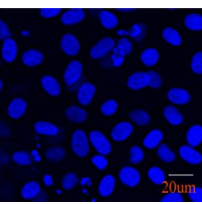

HPC

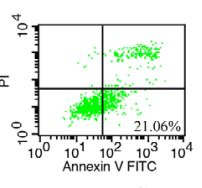

HPC

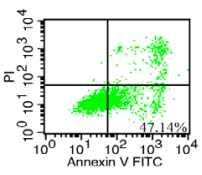

$\mathrm{HPC}+\mathrm{GA}$

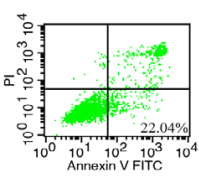

$\mathrm{HPC}+\mathrm{SOD}$
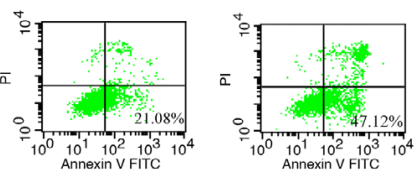

$\mathrm{HPC}+\mathrm{C}$-siRNA

HPC+HSP90-SiRNA

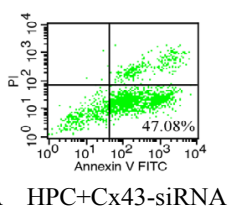

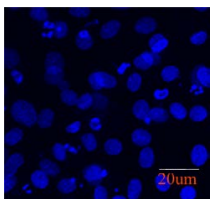

H/R

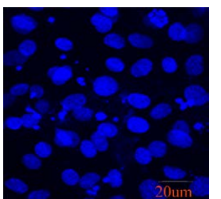

$\mathrm{HPC}+\mathrm{SC}$

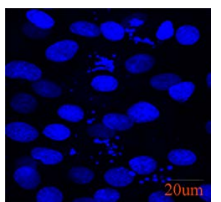

HPC

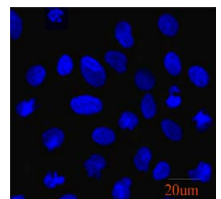

$\mathrm{HPC}+\mathrm{GA}$

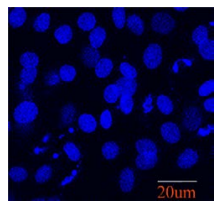

$\mathrm{HPC}+\mathrm{SOD}$ of cardiomyocyte

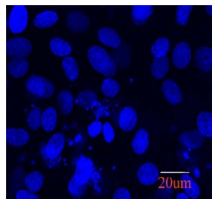

HPC + C-siRNA $\quad H P C+H S P 90-$ siRNA $\quad H P C+C x 43-s i R N A$

and H9c2 cell apoptosis by changes in nuclear morphology with Hoechst 33342 fluorescent dye; apoptoic cells exhibited abnormal morphologies including nuclear condensation, cell shrinkage, and nuclear fragmentation; magnification=×200; $n=4$ for each group.

We further studied the effect of HSP90 on the cardioprotection of HPC by inhibitiing HSP90 activity with the selective HSP90 inhibitor GA $(1 \mu \mathrm{M})$. As shown in lane 4 of Fig. 1A, GA abolished the increased expression of HSP90 (61.9 $\pm 1.2 \%$ vs $101.2 \pm 1.2 \%)$ and the apoptoticcardiomyocyte-limiting effect of HPC $(47.1 \pm 1.3 \%$ vs. $21.1 \pm 1.4 \%$ for Annexin V-FITC and $41.2 \pm 1.3 \%$ vs. $21.6 \pm 1.1 \%$ for Hoechst 33342 , respectively; P <0.05, Fig. $2 \mathrm{~A} \& \mathrm{C}$ ).

\section{KARGER}


Fig. 3. Effect of inhibiting HSP90 activity with geldanamycin $(\mathrm{GA}, 1 \mu \mathrm{M})$ on the expression of Bcl-2 and Bax in cardiomyocytes. (A) Representative Western blots showing the expression of $\mathrm{Na}^{+}-\mathrm{K}^{+}$-ATPase and COXIV in sarcolemmal and mitochondrial fractions in cardiomyocytes and H9c2 cells (control group); lanes 1 and 2, sarcolemma in cardiomyocytes and H9c2 cells; lanes 3 and 4 , mitochondria in cardiomyocytes and H9c2 cells. (B), (C) Representative Western blots showing the expression of Bcl-2 and Bax in sarcolemmal and mitochondrial fractions in cardiomyocytes with or without treatment with $\mathrm{GA} ; \mathrm{Na}^{+}-\mathrm{K}^{+}$-ATPase and COXIV were used to demonstrate equal protein loading, respectively. (D) Graphic representations of Bcl-2 and Bax expression; values in the graphs represent the mean \pm standard deviation; ${ }^{*} \mathrm{P}<0.05$ versus control group, ${ }^{\&} \mathrm{P}<0.05$ versus $\mathrm{H} / \mathrm{R}$ group, ${ }^{*} \mathrm{P}<0.05$ versus HPC group; $\mathrm{n}=4$ for each group.

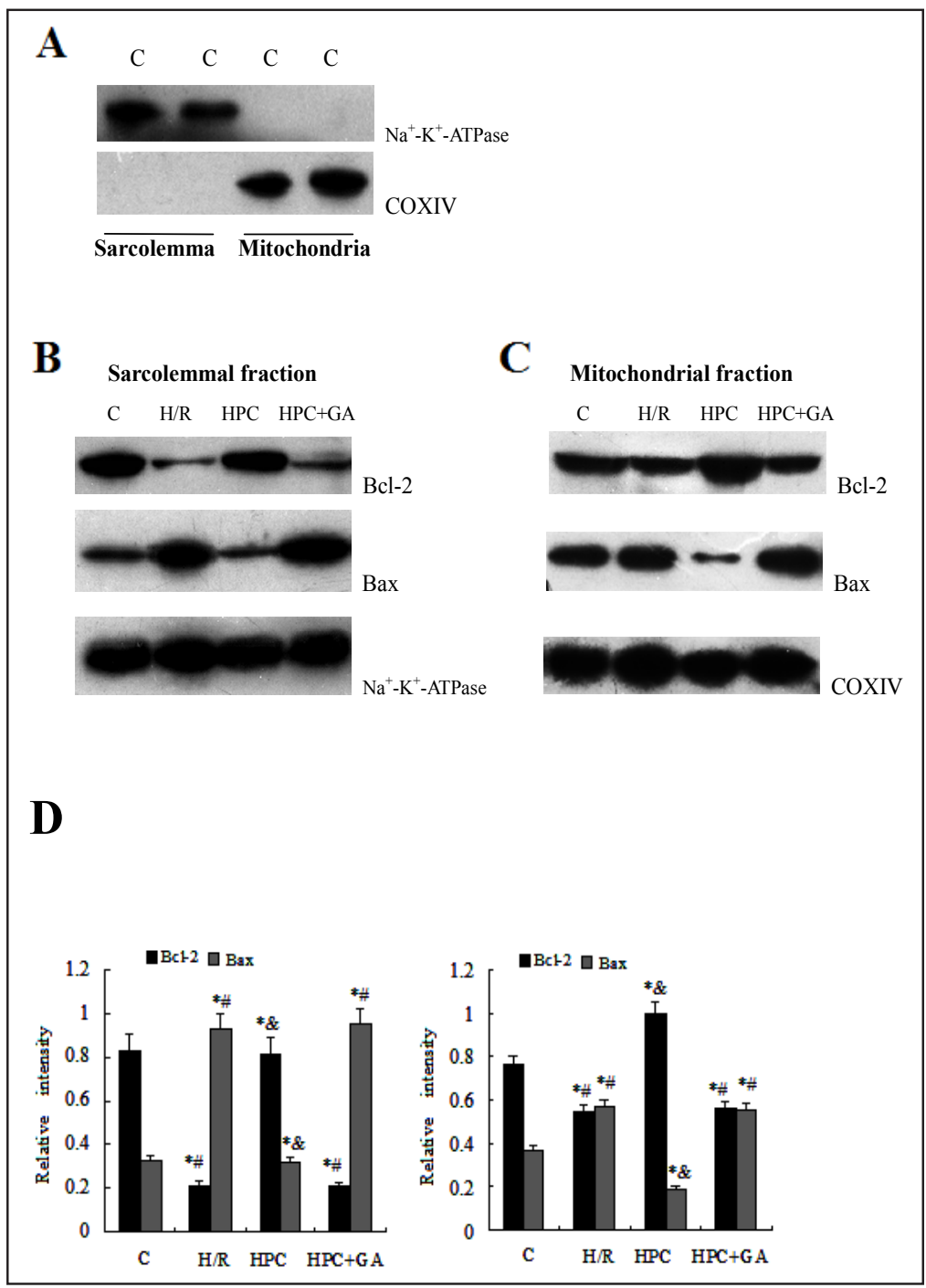

It is known that the HSP90 inhibitor has many nonspecific effects. To confirm the specific role of HSP90 on HPC cardioprotection, we examined the effect of suppressing endogenous HSP 90 with siRNAs targeting the HSP $90 \alpha$ and $\beta$ isoform s in the rat embryonic cardiomyoblastderived cell line H9c2. These cells, which were derived from embryonic rat heart, are used extensively as an in vitro model in studies exploring cardioprotection, heat shock proteins and protein kinases since they display similar morphological, electrophysiological, and biochemical properties to primary cardiomyocytes and are easily transfected $[15,16,24]$. Western blot analysis of cell lysates harvested at 48-72 $\mathrm{h}$ after transfection with siRNA directed against HSP90 revealed that the levels of HSP90 were dramatically decreased (3.6fold compared with control; P <0.05; Fig. 4A\&B). A negative control siRNA (C-siRNA) did not have any effect on the total protein level of HSP90 ( $>0.05$, compared with control group; Fig. 4A\&B). Then, we tested the change in apoptosis in H9c2 cells exposed to HPC. Similar to the results obtained for cardiomyocytes, HPC with three cycles of 5 min reoxygenation and 5 min hypoxia inhibited H9c2 cell apoptosis $(\mathrm{P}<0.05$, compared with H/R group; lane 2 in Fig. 2B\&D), and this effect was largely prevented by suppression of HSP90 with siRNA ( $\mathrm{P}<0.05$, compared with HPC group; lane 4 in Fig. 2B\&D). Transfection with C-siRNA had no impact on the apoptotic-cardiomyocyte-limiting effect of HPC (P $>0.05$, compared with HPC group; lane 3 in Fig. 2B\&D). Taken together, these results indicated that HSP90 was involved in the cardiomyocyte protection of HPC.

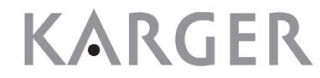


Fig. 4. Effect of inhibiting HSP90 activity with HSP90 SiRNA on the expression of Bcl-2 and Bax in H9c2 cells. (A) Western blot of the total cellular fraction from H9c2 cells transfected with HSP90-siRNA or C-siRNA; GAPDH was used to demonstrate equal protein loading. (C), (D) Representative Western blots showing the expression of Bcl-2 and Bax in sarcolemmal and mitochondrial fractions in $\mathrm{H} 9 \mathrm{c} 2$ cells with or without treatment with HSP90 siRNA; $\mathrm{Na}^{+}-\mathrm{K}^{+}$-ATPase and COXIV were used to demonstrate equal protein loading, respectively. (B) Graphic representation of HSP90 expression, (E) graphic representation of Bcl-2 and Bax expression; values in the graphs represent the mean \pm standard deviation; ${ }^{*} \mathrm{P}<0.05$ versus control group, ${ }^{\mathrm{P}} \mathrm{P}<$ 0.05 versus $\mathrm{H} / \mathrm{R}$ group, ${ }^{\#} \mathrm{P}<0.05$ versus HPC group; $n=4$ for each group.

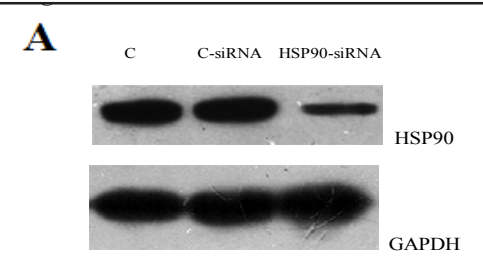

B

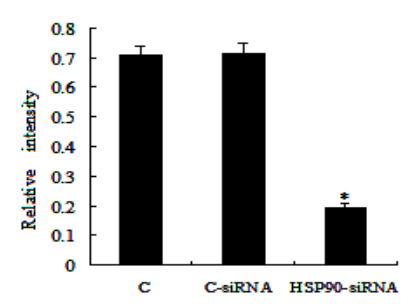

C

D
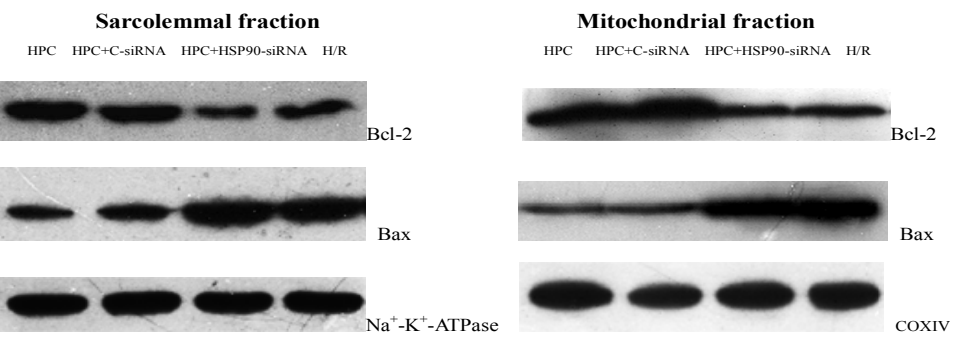

E

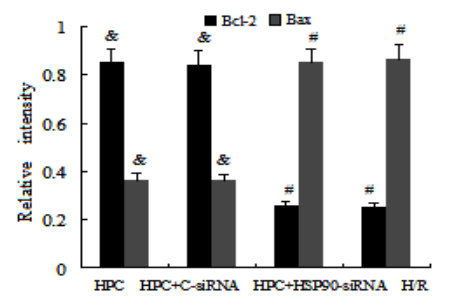

Role of HSP90 in expression of Bcl-2 and Bax proteins in mitochondrial and sarcolemmal fraction during hypoxic postconditioning

The Bcl-2 family plays a central role in the mitochondrial apoptotic pathway. To exhaustively investigate the role of the Bcl-2 family in HPC, we analyzed the distributions of Bcl-2 and Bax in the mitochondrial and sarcolemmal fractions isolated from cardiomyocytes. The purity and enrichment of mitochondria and sarcolemma were determined using antibody against COXIV and $\mathrm{Na}^{+} / \mathrm{K}^{+}$-ATPase. As shown in Fig. 3A, the mitochondrial fraction was highly enriched and free of sarcolemmal contamination, and the sarcolemmal fraction was highly enriched and free of mitochondrial contamination. HPC-treated cardiomyocytes exhibited higher levels of Bcl-2 and lower levels of Bax both in the mitochondrial and sarcolemmal fractions, $(\mathrm{P}<0.05$, compared with the $\mathrm{H} / \mathrm{R}$ group; mitochondria: $99.9 \pm 3.2 \% \mathrm{vs}$. $55 \pm 1 \%$ and $19.2 \pm 1.1 \%$ vs. $56.8 \pm 0.9 \%$, respectively; sarcolemma: $81.8 \pm 1.8 \%$ vs. $21.1 \pm 2.3 \%$ and $31.7 \pm 1.6 \%$ vs. $93.2 \pm 2 \%$, respectively; Fig. 3B-D), which was prevented by GA and siRNA against HSP90 $(\mathrm{P}<0.05$, compared with HPC group; lane 4 of Fig. 3B-D, lane 3 of Fig. 4CE). These results suggested that HPC protected the cardiomyocytes against H/R-induced apoptosis by increasing Bcl-2 and decreasing Bax mitochondrial and sarcolemmal levels. GA and HSP90-siRNA treatment counteracted the antiapoptotic effects of HPC by suppressing Bcl-2 and increasing Bax mitochondrial and sarcolemma levels.

\section{KARGER}


Fig. 5. Effect of inhibiting HSP90 activity with geldanamycin (GA, $1 \mu \mathrm{M}$ ) or HSP90SiRNA on mitochondrial targeting of $\mathrm{Cx} 43$ in cardiomyocytes and H9c2 cells. (A), (B) Representative Western blots showing the expression of total-Cx43 (TCx43) and phosphCx43 (PCx43) in sarcolemmal and mitochondrial fractions in cardiomyocytes with or without treatment with $\mathrm{GA} ; \mathrm{Na}^{+}-\mathrm{K}^{+}-$ ATPase and COXIV were used to demonstrate equal protein loading, respectively. (D), (E) Representative Western blots showing the expression of total-Cx43 and phosph-Cx43 in sarcolemmal and mitochondrial fractions in $\mathrm{H} 9 \mathrm{c} 2$ cells with or without treatment with HSP90-siRNA. (C), (F) Graphic representations of total-Cx43 and phosph-Cx43 expression; values in the graphs represent the mean \pm standard deviation; ${ }^{*} \mathrm{P}<0.05$ versus control group, ${ }^{\circledR} \mathrm{P}<0.05$ versus $\mathrm{H} / \mathrm{R}$ group, ${ }^{\#} \mathrm{P}<0.05$ versus HPC group; $\mathrm{n}=4$ for each group.

Role of HSP90 in mitochondrial targeting of Cx43 during hypoxic postconditioning

Since HSP90 has been linked to cardioprotection of ischemic preconditioning and mitochondrial import of $\mathrm{Cx} 43$, we tested whether HSP90 had the same effect as the promotion of $\mathrm{Cx} 43$ translocation into mitochondria during HPC. Western blot analysis using an antibody against total-Cx43 (TCx43) and phosph-Cx43 (PCx43) revealed a prominent protein band in the mitochondrial fraction compared with a faint band in the sarcolemmal fraction during HPC (Fig. 5A-C). These results indicated that HPC induced a significant redistribution of TCx43 and PCx43 from the sarcolemma to mito-
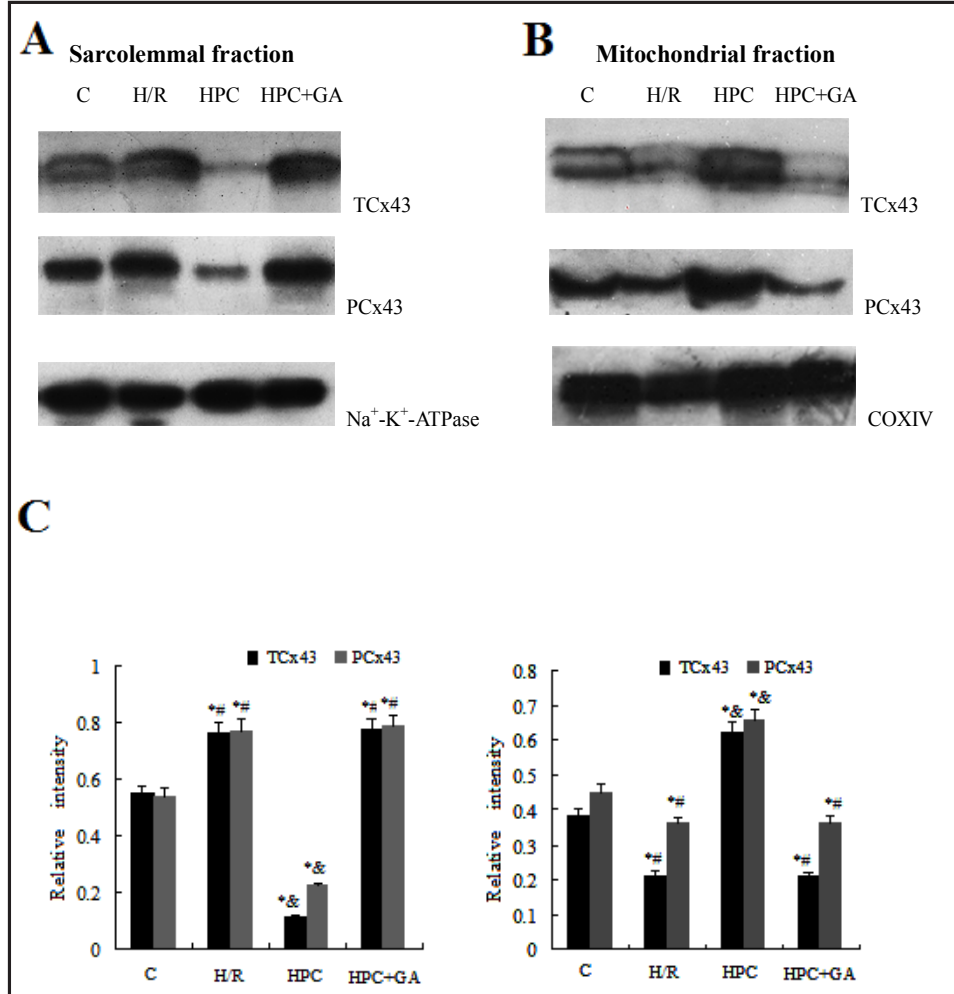

D
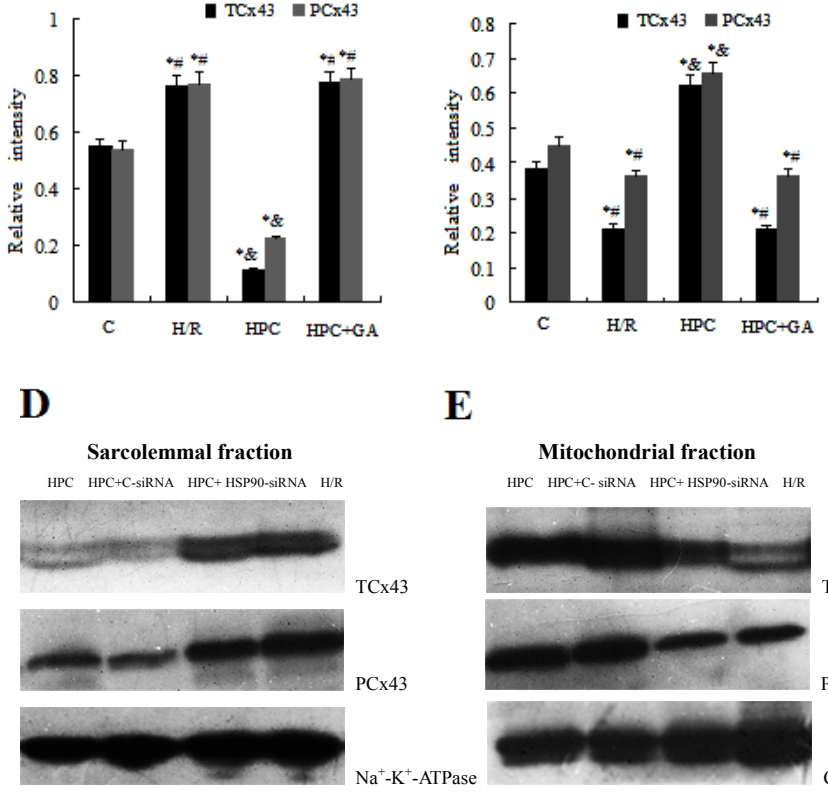

$\mathbf{E}$

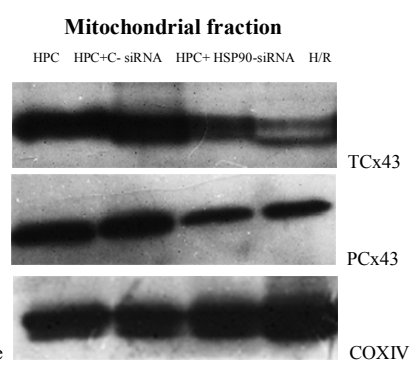

$\mathbf{F}$
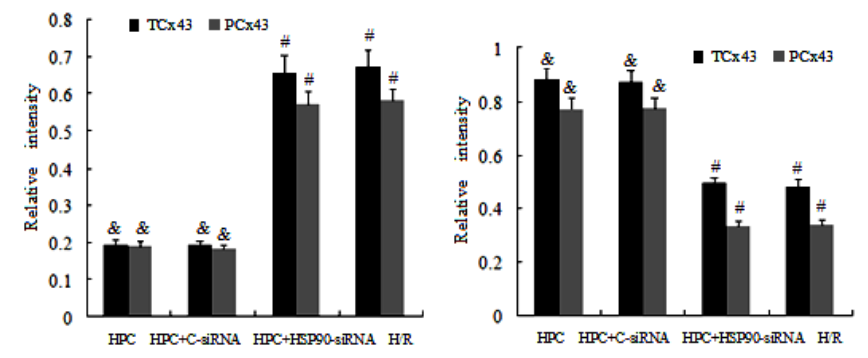


\section{Cellular Physiology and Biochemistry Published \begin{tabular}{l|l} 
DOI: 10.1159/000485399 & (c) 2017 The Author(s). Published by S. Karger AG, Basel \\
www.karger.com/cpb
\end{tabular} \\ Tu et al.: Heat Shock Protein 90 in Hypoxic Postconditioning}

Fig. 6. Effect of ROS scavengers or Cx43-siRNA on the production of mitochondrial ROS in cardiomyocytes and H9c2 cells. (A) Mitochondrial ROS production in cardiomyocytes with or without treatment with superoxide dismutase (SOD, 100U/mL), catalase (CAT, $120 \mathrm{U} / \mathrm{mL}$ ) and SOD plus CAT; values in the graphs represent the mean \pm standard deviation; ${ }^{*} \mathrm{P}<0.05$ versus control group, ${ }^{\&} \mathrm{P}<0.05$ versus $\mathrm{H} / \mathrm{R}$ group, ${ }^{\text {P }}<0.05$ versus HPC group; $\mathrm{n}=4$ for each group. (B) Mitochondrial ROS production in H9c2 cells with or without treatment with Cx43-siRNA; values in the graphs represent the mean \pm standard deviation; ${ }^{\&} \mathrm{P}<0.05$ versus $\mathrm{H} / \mathrm{R}$ group, ${ }^{\#} \mathrm{P}<0.05$ versus HPC group; $n=4$ for each group.

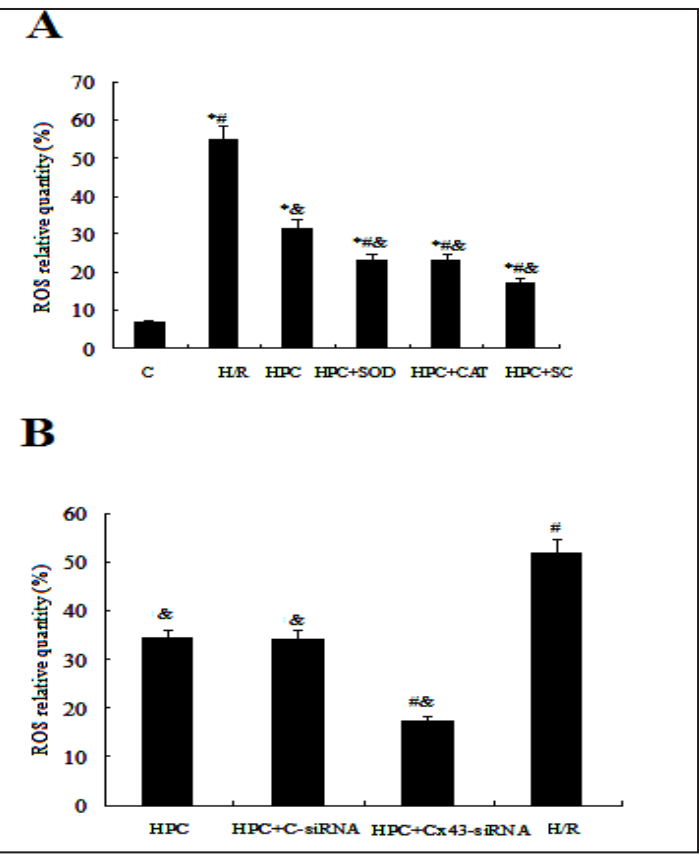

chondria. As shown in Fig. 5A-C, the mitochondria-to-sarcolemma ratios of TCx 43 and $\mathrm{PCx} 43$ increased significantly in the HPC group compared with the H/R group $(\mathrm{P}<0.05$, mitochondria: $62.2 \pm 1.3 \%$ vs. $21.2 \pm 0.7 \%$ and $65.5 \pm 1.0 \%$ vs. $36.1 \pm 1.3 \%$, respectively; sarcolemma: $11.6 \pm 1.1 \%$ vs. $76.2 \pm 1.2 \%$ and $22.3 \pm 1.7 \%$ vs. $76.9 \pm 1.4 \%$, respectively). The HSP90 inhibitor GA blocked the effect of HPC-induced translocation of TCx43 and PCx43 to mitochondria. Similar results were also obtained using siRNA against HSP90 $(\mathrm{P}<0.05$, compared with HPC group; Fig. 5D-F). These results indicated that HPC induced the translocation of $\mathrm{Cx} 43$ from sarcolemma to mitochondria via activation of HSP90.

\section{Role of mitochondrial Cx43-ROS during hypoxic postconditioning}

Mitochondrial $\mathrm{Cx} 43$ plays an important role in ischemic preconditioning, likely via modulation of the opening of mKATP channels and subsequent ROS signaling $[14,25]$. We sought to determine whether mitochondrial $\mathrm{Cx} 43$ is involved in HPC, underpinning the initial triggering role of ROS signaling and the subsequent reduction of redox stress. As shown in Fig. 6A, mitochondrial ROS production after H/R with $3 \mathrm{~h}$ of hypoxia and $6 \mathrm{~h}$ of reoxygenation was significantly increased, and this phenomenon was inhibited by HPC with three cycles of 5 min reoxygenation and 5 min hypoxia $(\mathrm{P}<0.05)$, suggesting that ROS might be cardioprotective at a low level but detrimental at a high level, and thus a moderate ROS level, lower than the level that initiates damage during in the early reoxygenation stage, is required to trigger effective cardioprotective signaling.

To determine the mechanism underlying ROS-induced cardioprotection of HPC, the ROS inhibitors SOD, CAT, and SOD plus CAT were utilized. As shown in Fig. 6, mitochondrial ROS production slightly decreased in response to HPC in the SOD or CAT group, but it decreased approximately 2 -fold in the HPC-treated SOD plus CAT group $(\mathrm{P}<0.05$, compared with HPC group). The remarkable reduction in mitochondrial ROS is consistent with the increase in cardiomyocytes apoptosis. As shown in Fig. 2A\&C, the number of apoptotic cardiomyocytes identified by Annexin V-FITC and Hoechst 33342 staining was significantly elevated in the SOD plus CAT treatment group (47.7 $\pm 1.0 \%$ and $40.2 \pm 1.3 \%$ ) compared with the HPC group $(21.1 \pm 1.4 \%$ and $21.6 \pm 1.1 \%)$. Intriguingly, neither SOD nor CAT treatment counteracted the antiapoptotic effects of HPC $(\mathrm{P}>0.05)$. Concomitantly, cardiomyocytes treated with SOD plus CAT exhibited lower levels of Bcl-2 and higher levels of Bax in both the mitochondrial 
Fig. 7. Effect of ROS scavenger on the expression of Bcl-2 and Bax in cardiomyocytes. (A), (B) Representative Western blots showing the expression of Bcl-2 and Bax in sarcolemmal and mitochondrial fractions in cardiomyocytes with or without treatment with superoxide dismutase (SOD, $100 \mathrm{U} / \mathrm{mL}$ ), catalase (CAT, 120 $\mathrm{U} / \mathrm{mL}$ ) and SOD plus CAT; $\mathrm{Na}^{+}-\mathrm{K}^{+}$ATPase and COXIV

A

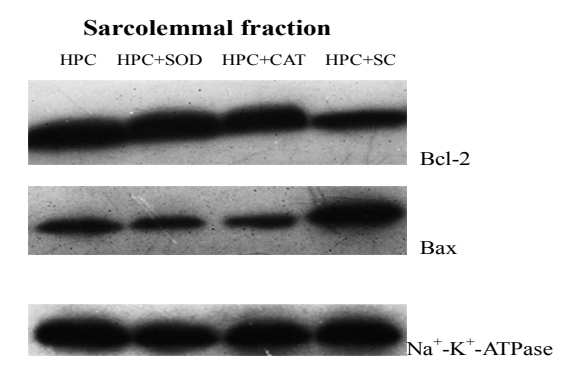

B

C

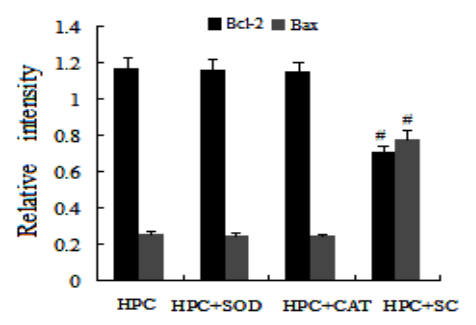

were used to dem-

onstrate equal protein loading, respectively. (C) Graphic representation of Bcl-2 and Bax expression; values in the graphs represent the mean \pm standard deviation; ${ }^{*} \mathrm{P}<0.05$ versus control group, ${ }^{\&} \mathrm{P}<0.05$ versus $\mathrm{H} / \mathrm{R}$ group, ${ }^{\mathrm{P}}<0.05$ versus $\mathrm{HPC}$ group; $\mathrm{n}=4$ for each group.

and sarcolemmal fractions, $(\mathrm{P}<0.05$, compared with HPC group, Fig. 7A-C). There were no significant differences among the HPC, HPC with SOD and HPC with CAT groups. Taken together, these data suggest that postconditioning relies on a certain level of ROS signaling, too much or too little mitochondrial ROS production is detrimental and inhibits the apoptoticand cardiomyocyte-limiting effect of HPC. Thus, maintenance of the ROS balance is a central feature of HPC protection.

The potential mechanisms involved in the ROS balance during HPC are presently unresolved. Here, we examined the role of $\mathrm{Cx} 43$ in the modulation of ROS signaling in HPC by examining the effect of $\mathrm{Cx} 43$ on cardioprotection through siRNA-reduced expression of $\mathrm{Cx} 43$. As shown in Fig. 8A \&B, transfection of H9c2 cells with Cx43-siRNA significantly reduced the expression of endogenous $\mathrm{Cx} 43$ (3.7 -fold compared with control; $\mathrm{P}<0.05$ ). Mitochondrial ROS production was also markedly inhibited by $\mathrm{Cx} 43$-siRNA $(\mathrm{P}<0.05$, Fig. $6 \mathrm{~B})$. The remarkable reduction in mitochondrial ROS is consistent with the increase in H9c2 cell apoptosis. As shown in Fig. 2B\&D, siRNA-Cx43 treatment significantly abolished the antiapoptotic effect of HPC. It also suppressed Bcl-2 and increased Bax mitochondrial and sarcolemmal levels (Fig. 8C-E). Therefore, our data suggest that mitochondrial $\mathrm{Cx} 43$ is involved in HPC cardioprotection, likely via modulation of the ROS balance.

\section{Discussion}

The key finding of the present study is that HPC enhances the translocation of Cx43 to the mitochondria in an HSP90-dependent manner. We showed that HPC significantly reduced H/R-induced cardiomyocyte apoptosis, modulated mitochondrial ROS production, and increased the expression of HSP90 protein at total and mitochondrial levels. We further demonstrated for the first time that HSP90, especially in the mitochondrial fraction, was 
Fig. 8. Effects of siRNA targeting $\mathrm{Cx} 43$ on the expression of $\mathrm{Bcl}-2$ and Bax in H9c2 cells. (A) Western blot of the total cellular fraction from H9c2 cells transfected with Cx43-siRNA or C-siRNA; GAPDH was used to demonstrate equal protein loading. (C), (D) Representative Western blots showing the expression of $\mathrm{Bcl}-2$ and Bax in sarcolemmal and mitochondrial fractions in H9c2 cells with or without treatment with siRNA-Cx43. (B) Graphic representation of Cx43 expression, (E) Graphic representation of Bcl-2 and Bax expression; values in the graphs represent the mean \pm standard deviation; ${ }^{*} \mathrm{P}<0.05$ versus control group, ${ }^{\&} \mathrm{P}<$ 0.05 versus $H / R$ group, ${ }^{\#} \mathrm{P}<0.05$ versus HPC group; $n=4$ for each group.
A

C C-siRNA Cx43-siRNA
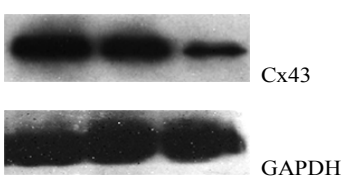

B

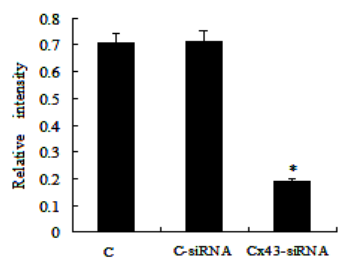

C

Sarcolemmal fraction HPC HPC+ siRNA HPC+Cx43-siRNA H/R

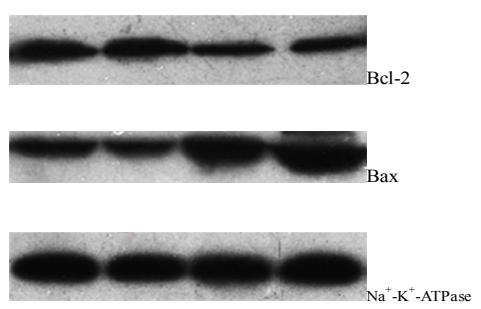

D

Mitochondrial fraction HPC $\quad H P C+$ siRNA HPC+Cx43-siRNA H/R

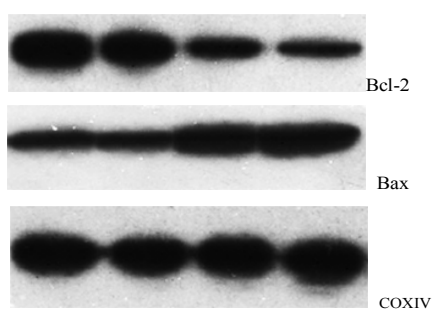

$\mathbf{E}$

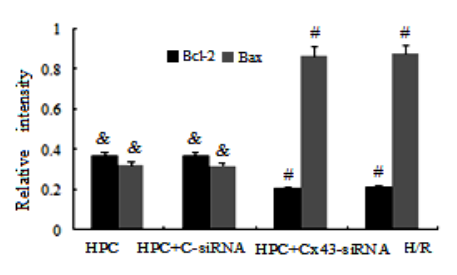

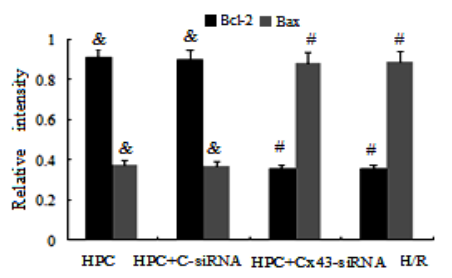

critical for Cx43-mediated cardioprotection against H/R-induced injury, possibly by promoting $\mathrm{Cx} 43$ targeting to mitochondria and subsequent ROS signaling, ultimately leading to a reduction in cardiomyocyte apoptosis and necrosis by induction of the antiapoptotic protein Bcl-2 and inhibition of proapoptotic Bax in the mitochondrial and sarcolemma fractions. Our data reveal a novel mechanism of HPC protection.

HSP90 is a molecular chaperone that is required for importing hydrophobic membrane proteins into mitochondria, especially during stress conditions [26]. We have previously reported that HSP90-mediated mitochondrial import of PKCepsilon plays a central role in protection of the myocardium against I/R injury [17]. It is well- known that HSP90-mediated mitochondrial import of $\mathrm{Cx} 43$ and adenosine triphosphate-sensitive $\mathrm{K}^{+}$channels is critical during preconditioning cardioprotection. In the present study, we assessed whether HPC had the same effect as preconditioning on promoting $\mathrm{Cx} 43$ translocation to mitochondria and whether HSP90 could modulate this effect. We showed that HPC increased the total and mitochondrial levels of HSP90 and the mitochondria-to-sarcolemma ratio of $\mathrm{Cx} 43$; suppressing the function of HSP90 with GA or HSP90-siRNA prevented the HPC-induced association of $\mathrm{Cx} 43$, indicating that mitochondrial HSP90 was important for the mitochondrial translocation of $\mathrm{Cx} 43$ during HPC. To the best of our knowledge, this is the first description of the interaction between mitochondrial HSP90 and the mitochondrial import of $\mathrm{Cx} 43$ in HPC, suggesting a possible mechanism for the mitochondrial translocation of $\mathrm{Cx} 43$.

\section{KARGER}




\section{Cellular Physiology Cell Physiol Biochem 2017;44:982-997

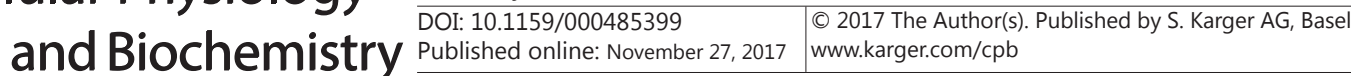 \\ Tu et al.: Heat Shock Protein 90 in Hypoxic Postconditioning}

The main gap junction protein, $\mathrm{Cx} 43$, is an emerging therapeutic target in I/R injury and cardioprotection [27]. In addition to the sarcolemma, $\mathrm{Cx} 43$ is also found in the inner mitochondrial membrane. It is well known that $\mathrm{Cx} 43$ mitochondrial targeting is a prerequisite for protection during preconditioning. Reduced levels of mitochondrial $\mathrm{Cx} 43$ abolishes the infarct size reduction caused by diazoxide in isolated rat hearts [28]. However, positive and negative results against reperfusion injuries have been obtained for $\mathrm{Cx} 43$ during postconditioning. Previous data have indicated that $\mathrm{Cx} 43$ does not appear to be important for cardioprotection during ischemic postconditioning [29]. However, recent studies have demonstrated that ischemic postconditioning decreases the rat infarct size by improving the expression of cellular membrane $\mathrm{Cx} 43$ [30]. Although increasing evidence suggests that $\mathrm{Cx} 43$ is linked to postconditioning [30-33], no studies have addressed the translocation of $\mathrm{Cx} 43$ to the mitochondria during postconditioning. The experiments presented herein were designed to determine whether postconditioning altered $\mathrm{Cx} 43$ in sarcolemmal and mitochondrial fractions. We found relatively low levels of TCx43 and PCx43 in mitochondria in the H/R group, but significantly higher levels in the HPC group. In contrast, the levels of TCx43 and $\mathrm{PCx} 43$ in the sarcolemma were relatively higher in the H/R group, but significantly lower in the HPC group, indicating that HPC induced a significant redistribution of $\mathrm{Cx} 43$ from the sarcolemma to mitochondria.

Most recently, a link between $\mathrm{Cx} 43$ and ROS formation has been provided. In fact, the main source of ROS in cardiomyocytes is located in mitochondria. While ROS are among the main determinants of cellular damage during longer periods of ischemia and reperfusion, there is also ample evidence that mitochondrial ROS signaling is linked to preconditioning and postconditioning cardioprotection [34, 35]. However, the precise mechanisms underlying the controversial roles of ROS in cardiomyocyte H/R injury and cardioprotection are not yet fully understood. In the present study, we found that a burst of ROS during reoxygenation was detrimental to cardiomyocytes, but a controlled amount of ROS generated during HPC triggered protective signaling and reduced cardiomyocyte apoptosis. HPC appeared to modulate the endogenous ROS balance. The signaling role of ROS is also consistent with the significant blunting of the protective effects of postconditioning in isolated rat hearts and human myocardium by the ROS scavenger N-acetyl-L-cysteine or $\mathrm{N}$-mercaptopropionylglycine [36, 37].

As the most common combination of ROS scavengers, SOD (eliminated $02^{*}$ ) and CAT (eliminated $\mathrm{H}_{2} \mathrm{O}_{2}$ ) have been intensively used to explore ROS signaling in cardioprotection during preconditioning and postconditioning. In the present study, to elucidate the underlying mechanism of ROS-mediated cardioprotection of HPC, neonatal rat cardiomyocytes were treated with SOD or CAT or SOD plus CAT. Mitochondrial ROS were significantly decreased in HPC with SOD plus CAT treatment compared with HPC with SOD or CAT treatment. Interestingly, the application of SOD or CAT during postconditioning did not abolish the anti-apoptotic effects of postconditioning, whereas postconditioning with SOD plus CAT prevented its anti-apoptotic effect. These findings might be due to the reliance of postconditioning on a certain level of ROS signaling; thus, unlike SOD plus CAT, either SOD or CAT could maintain endogenous ROS at the lowest possible level during early reoxygenation in HPC to reach the required threshold to trigger efficient cardioprotection. This result supports our observations indicating that maintenance of the ROS balance is a central aspect of HPC protection.

The potential mechanisms involved in the balance of ROS during HPC remain elusive. In the present study, we found that the HPC-induced ROS balance was accompanied by enhanced mitochondrial Cx43. Furthermore, a significant reduction of mitochondrial ROS production by siRNA-induced inhibition of $\mathrm{Cx} 43$ abolished the protection induced by HPC. Since postconditioning protection was Cx43-ROS-dependent, the concept emerged that $\mathrm{Cx} 43$ was essential for the cytoprotective signal transduction triggering ROS and subsequent reduction of redox stress.

Cardiomyocyte apoptosis, triggered by the bursts of ROS during reoxygenation, is a major mechanism underlying H/R injury. Accumulating studies have shown that the pro-

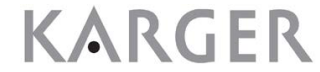


apoptotic (Bax) and anti-apoptotic (Bcl-2) proteins of the Bcl-2 family play a pivotal role in this apoptotic process [38] The balance between pro- and anti-apoptotic members of the Bcl-2 family is critical in determining cell fate. Apart from their localization at the mitochondria and the cytoplasm, Bcl-2 and Bax proteins are also constitutionally present on the sarcolemma of the cardiomyocytes [39]. Currently, the anti-apoptotic role of cytosolic Bcl2 in postconditioning cardioprotection has been well investigated in both in vivo and in vitro $[38,40]$, but little is known regarding the role of Bcl-2 family members in the sarcolemma and mitochondria. Here we examined the effects of HPC on Bcl-2 family proteins, especially in the sarcolemmal and mitochondrial fractions. We demonstrated that HPC blocked the decrease in Bcl-2 and increase in Bax that usually accompany H/R in both sarcolemmal and mitochondrial fractions of neonatal rat cardiomyocytes and H9c2 cells, confirming that the anti-apoptotic effect of HPC involved these two factors. The possible mechanism in which $\mathrm{HPC}$ regulates $\mathrm{Bcl}-2$ and $\mathrm{Bax}$ in sarcolemma and mitochondria is the inhibition of the bursts of ROS. It is well accepted that the main targets of ROS are sarcolemma and mitochondria of the cardiomyocytes. Indeed, sarcolemma damage remains the basis for utilizing intracellular components as biomarkers for clinical diagnosis of myocardial infarct. As a death signal, ROS may activate pro-apoptotic Bax in sarcolemma during reoxygenation. The activated Bax translocates to the mitochondria, and interacts with Bcl-2 and other members of the Bcl-2 family into complexes, thus facilitates the release of cytochrome c, and activates the mitochondrial apoptotic pathway [41, 42]. However, these bursts of ROS and activation of Bax were significantly inhibited by HPC. Furthermore, HPC increased sarcolemmal and mitochondrial levels of Bcl-2. Anti-apoptotic Bcl-2 protects the sarcolemma and the mitochondria by inhibiting Bax activation and subsequent mitochondrial translocation, thus preventing Bax from disrupting outer mitochondrial membrane integrity, and inhibiting the release of cytochrome $\mathrm{c}$ and subsequent procaspase activation. Future studies are needed to further define the function of Bcl-2 and Bax in sarcolemma and mitochondria in cardiomyocytes during HPC.

\section{Conclusion}

Mitochondrial HSP90 played a central role in HPC cardioprotection, and its activity was linked to the mitochondrial targeting of $\mathrm{Cx} 43$, the activation of which triggered ROS signaling and subsequent reduction of redox stress and resulted in the upregulation of its target gene Bcl-2 and inhibition of proapoptotic Bax in the sarcolemma and mitochondria, ultimately attenuating H/R-induced cardiomyocyte apoptosis. Our observations increase the body of knowledge concerning HPC-mediated cardioprotection against H/R injury and may lead to the identification of potential therapeutic targets.

\section{Acknowledgements}

This study was supported by grants from the National Natural Science Foundation of China (No. 81560068) and the Natural Science Foundation of Guangxi Province (No. 2015GXNSFAA139198).

\section{Disclosure Statement}

The authors reported no proprietary or commercial interest in any product mentioned or concept discussed in this article.

\section{References}

1 Zhao ZQ, Corvera JS, Halkos ME, Kerendi F, Wang NP, Guyton RA, Vinten-Johansen J: Inhibition of myocardial injury by ischemic postconditioning during reperfusion: comparison with ischemic preconditioning. Am J Physiol Heart Circ Physiol 2003;285:H579-588. 


\section{Cellular Physiology Cell Physiol Biochem 2017;44:982-997 \begin{tabular}{l|l|l} 
and Biochemistry Published onlIne: November 27, 2017 & $\begin{array}{l}\text { (c) } 2017 \text { The Author(s). Published by S. Karger AG, Basel } \\
\text { www.karger.com/cpb }\end{array}$ \\
\hline
\end{tabular}}

Tu et al.: Heat Shock Protein 90 in Hypoxic Postconditioning

2 Thuny F, Lairez O, Roubille F, Mewton N, Rioufol G, Sportouch C, Sanchez I, Bergerot C, Thibault H, Cung TT, Finet G, Argaud L, Revel D, Derumeaux G, Bonnefoy-Cudraz E, Elbaz M, Piot C, Ovize M, Croisille P: Postconditioning reduces infarct size and edema in patients with ST-segment elevation myocardial infarction. J Am Coll Cardiol 2012;59:2175-2181.

-3 Staat P, Rioufol G, Piot C, Cottin Y, Cung TT, L'Huillier I, Aupetit JF, Bonnefoy E, Finet G, Andre-Fouet X, Ovize M: Postconditioning the human heart. Circulation 2005;112:2143-2148.

-4 Thibault H, Piot C, Staat P, Bontemps L, Sportouch C, Rioufol G, Cung TT, Bonnefoy E, Angoulvant D, Aupetit JF, Finet G, Andre-Fouet X, Macia JC, Raczka F, Rossi R, Itti R, Kirkorian G, Derumeaux G, Ovize M: Long-term benefit of postconditioning. Circulation 2008;117:1037-1044.

5 Penna C, Rastaldo R, Mancardi D, Raimondo S, Cappello S, Gattullo D, Losano G, Pagliaro P: Postconditioning induced cardioprotection requires signaling through a redox-sensitive mechanism, mitochondrial ATP-sensitive K+ channel and protein kinase C activation. Basic Res Cardiol 2006;101:180189.

6 Helgeland E, Breivik L, Sishi BJ, Engelbrecht AM, Jonassen AK: Intermittent insulin treatment mimics ischemic postconditioning via MitoKATP channels, ROS, and RISK. Scand Cardiovasc J 2015;49:270-279.

- 7 Penna C, Perrelli MG, Tullio F, Angotti C, Camporeale A, Poli V, Pagliaro P: Diazoxide postconditioning induces mitochondrial protein S-nitrosylation and a redox-sensitive mitochondrial phosphorylation/ translocation of RISK elements: no role for SAFE. Basic Res Cardiol 2013;108:371.

-8 Song W, Sun J, Su B, Yang R, Dong H, Xiong L: Ischemic postconditioning protects the spinal cord from ischemia-reperfusion injury via modulation of redox signaling. J Thorac Cardiovasc Surg 2013;146:688695.

9 Vanden Hoek T, Becker LB, Shao ZH, Li CQ, Schumacker PT: Preconditioning in cardiomyocytes protects by attenuating oxidant stress at reperfusion. Circ Res 2000;86:541-548.

10 Gabrielova E, Kren V, Jaburek M, Modriansky M: Silymarin component 2, 3-dehydrosilybin attenuates cardiomyocyte damage following hypoxia/reoxygenation by limiting oxidative stress. Physiol Res 2015;64:79-91.

11 Alesutan I, Voelkl J, Stockigt F, Mia S, Feger M, Primessnig U, Sopjani M, Munoz C, Borst O, Gawaz M, Pieske B, Metzler B, Heinzel F, Schrickel JW, Lang F: AMP-activated protein kinase alpha1 regulates cardiac gap junction protein connexin 43 and electrical remodeling following pressure overload. Cell Physiol Biochem 2015;35:406-418.

12 Denuc A, Nunez E, Calvo E, Loureiro M, Miro-Casas E, Guaras A, Vazquez J, Garcia-Dorado D: New proteinprotein interactions of mitochondrial connexin 43 in mouse heart. J Cell Mol Med 2016;20:794-803.

13 Boengler K, Konietzka I, Buechert A, Heinen Y, Garcia-Dorado D, Heusch G, Schulz R: Loss of ischemic preconditioning's cardioprotection in aged mouse hearts is associated with reduced gap junctional and mitochondrial levels of connexin 43. Am J Physiol Heart Circ Physiol 2007;292:H1764-1769.

14 Boengler K, Dodoni G, Rodriguez-Sinovas A, Cabestrero A, Ruiz-Meana M, Gres P, Konietzka I, Lopez-Iglesias C, Garcia-Dorado D, Di Lisa F, Heusch G, Schulz R: Connexin 43 in cardiomyocyte mitochondria and its increase by ischemic preconditioning. Cardiovasc Res 2005;67:234-244.

$>15$ Jiao JD, Garg V, Yang B, Hu K: Novel functional role of heat shock protein 90 in ATP-sensitive K+ channelmediated hypoxic preconditioning. Cardiovasc Res 2008;77:126-133.

-16 Yang Z, Sun W, Hu K: Molecular mechanism underlying adenosine receptor-mediated mitochondrial targeting of protein kinase C. Biochim Biophys Acta 2012;1823:950-958.

-17 Zhong GQ Tu RH, Zeng ZY, Li QJ, He Y, Li S, He Y, Xiao F: Novel functional role of heat shock protein 90 in protein kinase C-mediated ischemic postconditioning. J Surg Res 2014;189:198-206.

18 Rodriguez-Sinovas A, Boengler K, Cabestrero A, Gres P, Morente M, Ruiz-Meana M, Konietzka I, Miro E, Totzeck A, Heusch G, Schulz R, Garcia-Dorado D: Translocation of connexin 43 to the inner mitochondrial membrane of cardiomyocytes through the heat shock protein 90-dependent TOM pathway and its importance for cardioprotection. Circ Res 2006;99:93-101.

-19 Sun HY, Wang NP, Halkos ME, Kerendi F, Kin H, Wang RX, Guyton RA, Zhao ZQ: Involvement of Na+/H+ exchanger in hypoxia/re-oxygenation-induced neonatal rat cardiomyocyte apoptosis. Eur J Pharmacol 2004;486:121-131.

20 Garg V, Hu K: Protein kinase C isoform-dependent modulation of ATP-sensitive K+ channels in mitochondrial inner membrane. Am J Physiol Heart Circ Physiol 2007;293:H322-332. 


\section{Cellular Physiology Cell Physiol Biochem 2017;44:982-997 \begin{tabular}{l|l|l|l|l}
\hline DOI: 10.1159/000485399 & $\begin{array}{l}\text { C) } 2017 \text { The Author(s). Published by S. Karger AG, Basel } \\
\text { www.karger.com/cpb }\end{array}$ \\
\hline and Biochemistry
\end{tabular}

-21 Bradford MM: A rapid and sensitive method for the quantitation of microgram quantities of protein utilizing the principle of protein-dye binding. Anal Biochem 1976;72:248-254.

22 Bording-Jorgensen M, Alipour M, Wine E, Danesh G: Inflammasome Activation by ATP Enhances Citrobacter rodentium Clearance through ROS Generation. Cell Physiol Biochem 2017;41:193-204.

-23 Van Acker H, Gielis J, Acke M, Cools F, Cos P, Coenye T: The Role of Reactive Oxygen Species in AntibioticInduced Cell Death in Burkholderia cepacia Complex Bacteria. PLoS One 2016;11:e0159837.

-24 Fretwell L, Dickenson JM: Role of large-conductance Ca(2)+-activated K+ channels in adenosine A(1) receptor-mediated pharmacological postconditioning in H9c2 cells. Can J Physiol Pharmacol 2011;89:2430.

25 Boengler K, Ungefug E, Heusch G, Leybaert L, Schulz R: Connexin 43 impacts on mitochondrial potassium uptake. Front Pharmacol 2013;4:73.

-26 Young JC, Hoogenraad NJ, Hartl FU: Molecular chaperones Hsp90 and Hsp70 deliver preproteins to the mitochondrial import receptor Tom70. Cell 2003;112:41-50.

-27 Schulz R, Gorge PM, Gorbe A, Ferdinandy P, Lampe PD, Leybaert L: Connexin 43 is an emerging therapeutic target in ischemia/reperfusion injury, cardioprotection and neuroprotection. Pharmacol Ther 2015;153:90-106.

28 Heinzel FR, Luo Y, Li X, Boengler K, Buechert A, Garcia-Dorado D, Di Lisa F, Schulz R, Heusch G: Impairment of diazoxide-induced formation of reactive oxygen species and loss of cardioprotection in connexin 43 deficient mice. Circ Res 2005;97:583-586.

29 Heusch G, Buchert A, Feldhaus S, Schulz R: No loss of cardioprotection by postconditioning in connexin 43-deficient mice. Basic Res Cardiol 2006;101:354-356.

30 He H, Li N, Zhao Z, Han F, Wang X, Zeng Y: Ischemic postconditioning improves the expression of cellular membrane connexin 43 and attenuates the reperfusion injury in rat acute myocardial infarction. Biomed Rep 2015;3:668-674.

-31 Bian B, Yu XF, Wang GQ, Teng TM: Role of miRNA-1 in regulating connexin 43 in ischemia-reperfusion heart injury: a rat model. Cardiovasc Pathol 2017;27:37-42.

-32 Bian B, Yu X, Wang Q Teng T, Nie J: Atorvastatin protects myocardium against ischemia-reperfusion arrhythmia by increasing Connexin 43 expression: A rat model. Eur J Pharmacol 2015;768:13-20.

-33 Wu Y, Gu EW, Zhu Y, Zhang L, Liu XQ, Fang WP: Sufentanil limits the myocardial infarct size by preservation of the phosphorylated connexin 43. Int Immunopharmacol 2012;13:341-346.

34 Perrelli MG, Tullio F, Angotti C, Cerra MC, Angelone T, Tota B, Alloatti G, Penna C, Pagliaro P: Catestatin reduces myocardial ischaemia/reperfusion injury: involvement of PI3K/Akt, PKCs, mitochondrial KATP channels and ROS signalling. Pflugers Arch 2013;465:1031-1040.

-35 Penna C, Perrelli MG, Pagliaro P: Mitochondrial pathways, permeability transition pore, and redox signaling in cardioprotection: therapeutic implications. Antioxid Redox Signal 2013;18:556-599.

-36 Yao YT, Li LH, Chen L, Wang WP, Li LB, Gao CQ: Sevoflurane postconditioning protects isolated rat hearts against ischemia-reperfusion injury: the role of radical oxygen species, extracellular signal-related kinases 1/2 and mitochondrial permeability transition pore. Mol Biol Rep 2010;37:2439-2446.

-37 Lemoine S, Buleon C, Rouet R, Ivascau C, Babatasi G, Massetti M, Gerard JL, Hanouz JL: Bradykinin and adenosine receptors mediate desflurane induced postconditioning in human myocardium: role of reactive oxygen species. BMC Anesthesiol 2010;10:12.

-38 Wu J, Yu J, Xie P, Maimaitili Y, Wang J, Yang L, Ma H, Zhang X, Yang Y, Zheng H: Sevoflurane postconditioning protects the myocardium against ischemia/reperfusion injury via activation of the JAK2-STAT3 pathway. PeerJ 2017;5:e3196.

-39 Sun Z, Zhang S, Liu L, Hasichaolu: Regulatory effect of bcl-2 family proteins in CPB-induced cardiomyocyte apoptosis in dog hearts. J Huazhong Univ Sci Technolog Med Sci 2002;22:103-106.

>0 Xie P, Yang L, Talaiti A, Wu JJ, Yu J, Yu T, Wang HY, Huang B, Wu Q, Maimaitili Y, Wang J, Ma HP, Yang YN, Zheng H: Deferoxamine-activated hypoxia-inducible factor-1 restores cardioprotective effects of sevoflurane postconditioning in diabetic rats. Acta Physiol (Oxf) 2017;221:98-114.

-41 Sakuragi N, Salah-eldin AE, Watari H, Itoh T, Inoue S, Moriuchi T, Fujimoto S: Bax, Bcl-2, and p53 expression in endometrial cancer. Gynecol Oncol 2002;86:288-296.

-42 Eskes R, Desagher S, Antonsson B, Martinou JC: Bid induces the oligomerization and insertion of Bax into the outer mitochondrial membrane. Mol Cell Biol 2000;20:929-935. 